\title{
Bruno Dumons, Christian Sorrel (dir.), Le catholicisme en chantiers, France, $\mathrm{XIX}^{\mathrm{e}}-\mathrm{XX}^{\mathrm{e}}$ siècles
}

Rennes, Presses universitaires de Rennes, 2013, 552 p

\section{Charles Mercier}

\section{OpenEdition}

Journals

Édition électronique

URL : http://journals.openedition.org/assr/26376

DOI : $10.4000 /$ assr.26376

ISSN : 1777-5825

Éditeur

Éditions de l'EHESS

Édition imprimée

Date de publication : 31 décembre 2014

Pagination : 171

ISBN : 978-2-7132-2467-6

ISSN : 0335-5985

Référence électronique

Charles Mercier, «Bruno Dumons, Christian Sorrel (dir.), Le catholicisme en chantiers, France, $\mathrm{xIx}^{\mathrm{e}}-\mathrm{xx}^{\mathrm{e}}$ siècles ", Archives de sciences sociales des religions [En ligne], 168 | 2014, mis en ligne le 03 septembre 2015, consulté le 22 septembre 2020. URL : http://journals.openedition.org/assr/26376 ; DOI : https:// doi.org/10.4000/assr.26376

Ce document a été généré automatiquement le 22 septembre 2020.

(C) Archives de sciences sociales des religions 


\section{Bruno Dumons, Christian Sorrel (dir.), Le catholicisme en chantiers, France, $\mathrm{XIX}^{\mathrm{e}}-\mathrm{XX}^{\mathrm{e}}$ siècles}

Rennes, Presses universitaires de Rennes, 2013, 552 p

Charles Mercier

\section{RÉFÉRENCE}

Bruno Dumons, Christian Sorrel (dir.), Le catholicisme en chantiers, France, $\mathrm{XIX}^{\mathrm{e}}$-XX ${ }^{\mathrm{e}}$

siècles, Rennes, Presses universitaires de Rennes, 2013, $552 p$ 
1 À l'heure où les invitations à l'interdisciplinarité, au comparatisme et à la dénationalisation des cadres d'analyse structurent de plus en plus le paysage de la recherche, ce livre collectif, centré sur l'historiographie du catholicisme français, qui ne regroupe que des contributions d'historiens, pourrait paraître comme un repli sur un territoire homogène, mais menacé dans le champ académique. Alors que les précédentes synthèses du genre étaient bâties sur un parti pris de dépassement des frontières confessionnelles (Jean-Marie Mayeur [dir.], L'histoire religieuse de la France, $19^{e}-20^{e}$ siècle, problèmes et méthodes, 1975) et nationales (Benoît Pellistrandi [dir.], L'histoire religieuse en France et en Espagne, 2004), Bruno Dumons et Christian Sorrel, tous deux membres du Laboratoire de

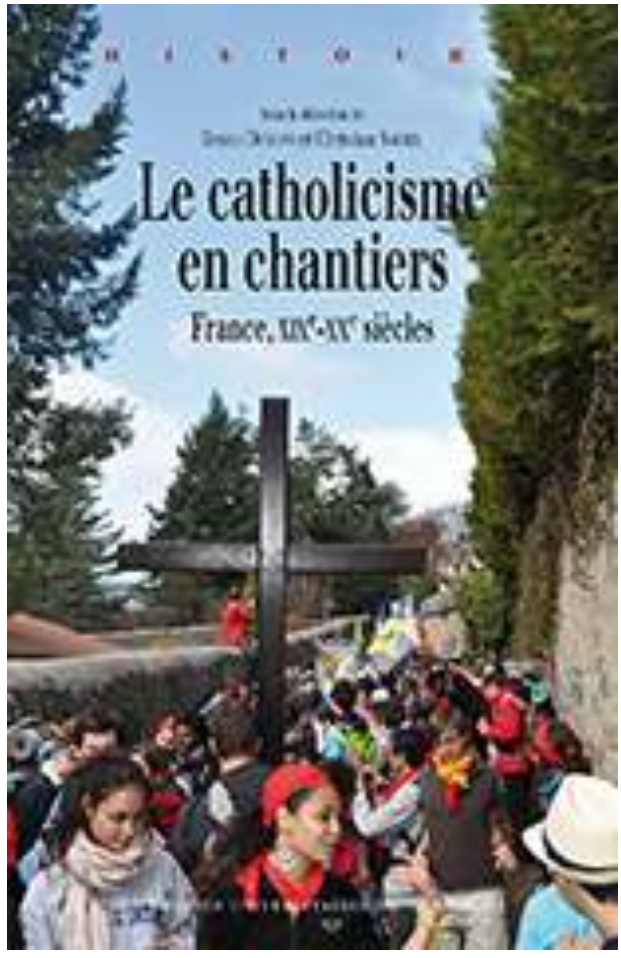
recherche historique Rhône-Alpes

(LAHRA), ont fait le choix de revenir aux périmètres du dernier tome de l'Histoire du catholicisme en France publié en 1962 par André Latreille - une des figures tutélaires de l'histoire religieuse à Lyon - avec le concours de René Rémond : l'histoire, la France, le catholicisme, la période contemporaine.

2 La lecture de l'ouvrage montre que ce retour aux origines n'est en fait nullement une régression. Il constitue une sorte de ré-enracinement préalable à la recherche de nouvelles ouvertures, dans un contexte où l'histoire du fait religieux catholique doit se réinventer pour maintenir sa place à l'université. De fait, les quatorze contributions organisées en quatre thématiques (1. Politique et culture, 2. Société et changement social, 3. Institutions et pratiques, 4. Circulations et connexions) ne se contentent pas d'offrir au lecteur des synthèses particulièrement précises et accessibles sur ce qui a été réalisé et ce qui reste à faire. Elles suggèrent des pistes pour re-légitimer socialement et intellectuellement une histoire savante du catholicisme français contemporain, à travers son aggiornamiento.

3 À l'instar des générations précédentes, qui avaient su déghettoïser l'histoire du catholicisme en l'insérant dans les courants dynamiques de l'historiographie - histoire sérielle, histoire des mentalités, histoire politique et culturelle - plusieurs contributeurs soulignent la nécessité d'un amarrage à l'histoire générale telle qu'elle s'est renouvelée (Guillaume Cuchet, p. 192) et proposent de lancer des ponts vers de nouveaux territoires, pas seulement pour se les approprier, mais aussi pour que ceux qui y travaillent puissent prendre le catholicisme pour objet d'étude. Jean-Pierre Moisset, déplorant la coupure entre historiens du catholicisme contemporain d'un côté et historiens des entreprises et des organisations de l'autre, cherche à établir des jonctions afin que l'Église catholique puisse être étudiée dans le champ de l'histoire économique et que l'intérêt pour la question des ressources matérielles et financières soit davantage présent dans le champ de l'histoire religieuse. Penser le catholicisme 
avec des cadres interprétatifs forgés dans d'autres sphères lui permet de renouveler sa compréhension et de dépasser les reformulations, sur un mode savant, des explications indigènes (p. 146-147). Matthieu Brejon de Lavergnée et Bruno Dumons montrent comment l'approche historique du catholicisme contemporain peut être fécondée par l'histoire du genre, notamment sur les questions de vocation religieuse, d'engagement militant, de rayonnement missionnaire ou de direction de conscience (p.95-97 et 125-127). On notera que, contrairement à "la génération de la percée " (Étienne Fouilloux), qui avait fait de la rencontre avec les autres sciences sociales - en premier lieu la sociologie religieuse, mais aussi la science politique - un des axes du renouvellement de l'histoire du catholicisme, la pluridisciplinarité est relativement peu évoquée dans ce volume, si ce n'est par Claude Prudhomme, qui montre comment l'histoire des missions catholiques est profondément nourrie par l'apport de la démarche anthropologique (p. 235-236). Si les autres contributeurs explorent peu cette voie, c'est peut-être parce que les synergies entre sociologues, politistes et historiens du catholicisme sont d'ores et déjà très actives, comme le prouvent les citations récurrentes d'Émile Poulat, de Danièle Hervieu-Léger et de Philippe Portier ou, pour la plus jeune génération, de Céline Béraud et de Magali Della Sudda.

4 C'est davantage dans l'ouverture internationale que les historiens rassemblés semblent percevoir une possibilité de rebond. L'écriture d'une histoire européenne et transnationale du catholicisme en phase avec l'histoire connectée et l'histoire globale (Bruno Dumons et Christian Sorrel, p. 14) permettrait de mieux saisir les singularités nationales, les interdépendances et les processus de transferts. Dans cette perspective, Vincent Petit et Florian Michel, lui-même engagé dans une histoire atlantique du catholicisme, soulignent tout l'intérêt qu'il y aurait à étudier les modalités de la réforme liturgique des années 1960 en mettant en regard le modèle français avec les situations anglaise, allemande, et italienne (p.180). Jean-Dominique Durand pointe comment l'étude des archives du Saint-Siège permet non seulement de mettre à jour le poids de la papauté dans les relations internationales mais aussi dans la vie des Églises nationales (p. 214-217).

5 La communication de Dominique Avon explore pour sa part le comparatisme interreligieux comme chemin de régénération. Si l'étude des différentes modalités des relations entre groupes religieux est bien entamée, le compartimentage confessionnel, malgré les affichages institutionnels, demeure vivace quand il s'agit d'écrire l'histoire des groupes religieux. La mise en comparaison du catholicisme français contemporain avec les religions non chrétiennes, et plus généralement avec "l'autre", est un chantier où tout reste pratiquement à faire et qui pourrait être extrêmement fécond (p. 261-265). Cette contribution reformule à nouveaux frais, dans un contexte où le pluralisme confessionnel s'est accentué, la proposition émise par Claude Langlois il y a bientôt quarante ans: insérer l'histoire du catholicisme dans l'étude plus large du phénomène religieux, lui-même délimité de manière extensive afin de ne pas le réduire à ses manifestations institutionnelles et tenir compte de ses reconfigurations dans le contexte de la modernité (dans Jean-Marie Mayeur [dir.], Ibid., p. 230).

6 À côté de ces propositions de décloisonnements, d'autres contributions montrent que l'histoire du catholicisme peut faire du neuf sur des thèmes déjà bien traités l'inscription dans les territoires (Olivier Chatelan), le clergé et les communautés (Bruno Dumons et Christian Sorrel), les dissidences et les marges (Jean-Pierre Chantin) - à condition de renouveler les approches. Frédéric Gugelot insiste sur 
l'intérêt de continuer à analyser l'évolution de la pensée catholique, non seulement parce que des archives deviennent accessibles, mais aussi parce que les approches de l'histoire intellectuelle ont évolué, avec une attention nouvelle à l'amont et à l'aval des textes imprimés: étude des processus d'écriture et de publication, analyse de la réception des œuvres, etc. (p. 57-64). Vincent Petit et Florian Michel montrent pour leur part que la liturgie ne doit pas constituer la chasse gardée de quelques clercs érudits mais qu'elle peut être appréhendée avec profit par l'historien, en tant qu'expérience sensible dans laquelle s'expriment des sensibilités religieuses au monde parfois antagonistes (p. 170-173).

On l'aura compris, cette réflexion collective, menée à la fois par des universitaires confirmés et des jeunes chercheurs - dont beaucoup ont été récemment recrutés sur des postes de maîtres de conférences ou de professeurs d'université orientés, au moins en partie, vers des thématiques d'histoire religieuse - permet d'ouvrir des voies. Cela suffira-t-il à consolider l'assise académique de l'histoire contemporaine du catholicisme? Rien n'est moins sûr, tant, comme le notent d'ailleurs les différents articles, les facteurs externes (contexte politique, configuration intellectuelle, demande sociale...) sont déterminants dans l'évolution d'un champ scientifique. De ce point de vue, l'affirmation récente d'une partie des catholiques comme force politique contestataire, à l'occasion de l'ouverture du mariage civil aux couples de même sexe, contribue à susciter des besoins d'intelligibilité auxquels l'histoire pourrait en partie répondre: les synthèses de Bruno Dumons et de Frédéric Le Moigne sur les rapports entre catholicisme et politique révèlent à quel point le passé éclaire le présent. L'entrée dans l'arène, au moment de l'offensive anticléricale du gouvernement de WaldeckRousseau (1899-1902), des dames d'œuvres catholiques (p.33), permet de mettre utilement en perspective la montée en puissance en 2013 d'une Frigide Barjot ou d'une Ludovine de La Rochère. La connaissance des circonstances de l'affrontement, au milieu des années 1920, entre le Cartel des gauches et la Fédération nationale catholique ouvre la possibilité d'une saisie, par analogie avec les récentes mobilisations, des invariants de la manifestation catholique de masse. Ce n'est pas le moindre des mérites de ce livre que de faire prendre conscience au lecteur combien la somme des connaissances déjà produites au sujet du catholicisme contemporain en France constitue un capital précieux pour mieux comprendre notre époque. 